\title{
Trichoderma Asal Akar Kopi Dari Alor: Karakterisasi Morfologi dan Keefektifannya Menghambat Colletotrichum Penyebab Penyakit Antraknosa secara in Vitro.
}

\section{Trichoderma of Coffee Roots From Alor: Morphological characteristic and in vitro Efficacy to Inhibit Colletotrichum Causing Anthracnose}

\author{
Didiana Yanuarita Molebila $^{1 *}$, Ade Rosmana ${ }^{2}$, Untung Surapaty Tresnaputra ${ }^{2}$ \\ ${ }^{1}$ Universitas Tribuana Kalabahi, Alor 85811 \\ ${ }^{2}$ Universitas Hasanuddin, Makassar 90245
}

\begin{abstract}
ABSTRAK
Trichoderma merupakan cendawan yang mampu berasosiasi dengan sistem perakaran tanaman kopi. Penelitian ini bertujuan mengetahui karakteristik morfospesies Trichoderma sp. dari akar kopi asal Alor, Nusa Tenggara Timur (NTT) dan menguji kemampuannya dalam menghambat perkembangan Colletotrichum sp. penyebab penyakit antraknosa secara in vitro. Sampel akar tanaman kopi sehat diambil dari perkebunan kopi di kabupaten Alor, NTT. Isolasi cendawan Trichoderma dari akar kopi dilakukan dengan menginkubasikan akar kopi yang telah disterilkan terlebih dahulu pada lapisan kertas saring lembab dalam cawan petri selama tujuh hari. Identifikasi Trichoderma dengan pengamatan ciri koloni pada medium agar-agar dekstrosa kentang (ADK) dan mikroskopis menggunakan mikrokultur (slide culture). Penghambatan cendawan Trichoderma terhadap Colletotrihum diuji dengan metode kultur ganda pada medium ADK. Hasil inkubasi akar pada kondisi lembab menunjukan adanya empat morfospesies Trichoderma yang memiliki perbedaan karakteristik yang spesifik. Uji antagonisme in vitro pada medium ADK terhadap tiga morfospesies Trichoderma menunjukan bahwa masing-masing dapat menghambat berturut-turut $70.2 \%, 65.8 \%$, dan $63.3 \%$ pada lima hari setelah inokulasi. Data ini memperlihatkan bahwa Trichoderma yang diisolasi dari akar kopi asal Alor berpotensi untuk menekan pertumbuhan patogen antraknosa.
\end{abstract}

Kata kunci: Colletotrichum, in vitro, karakterisasi morfologi.

\begin{abstract}
Trichoderma is a fungus capable of intimate associations with plant root systems including on coffee plants. This aim of study is to determine the characteristics of Trichoderma morphospecies from coffee roots of Alor origin, East Nusa Tenggara (NTT) and its ability to inhibit the growth of Colletotrichum causing anthracnose disease in vitro. Root samples of healthy coffee plants were taken from the location of coffee plantations in Alor District, NTT. Isolation of Trichoderma fungi from coffee roots was done by incubating the sterilized coffee roots in a layer of moist filter paper in a petri dish for seven days. Identification of Trichoderma by observing the characteristics of the colony on the medium of potato dextrose agar (PDA) and microscopic media using microcultures (slide culture). Inhibition of Trichoderma fungi against Colletotrichum was tested by multiple culture methods on PDA. The results of root incubation in humid conditions showed that there was four morphospecies of Trichoderma fungi, each of which had different characteristic specifications. In vitro antagonism in test on PDA, the first
\end{abstract}

*Alamat penulis korespondensi: Fakultas Pertanian dan Perikanan, Universitas Tribuana Kalabahi. Kel. Welai Timur, Kec. Teluk. Mutiara, Kabupaten Alor, Nusa Tenggara Timur. 85811

Surel: yanuarita.didiana187@gmail.com 
three morphospecies against Colletotrichum showed that each Trichoderma could inhibit $70.2 \%, 65.8 \%$, and $63.3 \%$, respectively, five days after inoculation. This data shows that Trichoderma isolated from coffee roots from Alor has the potential to suppress the growth of anthracnose pathogens.

Key words: Colletotrichum, in vitro, morphology characterization.

\section{PENDAHULUAN}

Trichoderma spp. merupakan salah satu agens hayati yang berpotensi untuk mengendalikan sejumlah patogen seperti Phythophthora capsici pada vanili (Taufiq 2012), Phytopthora palmivora pada kakao (Hakkar et al. 2014), Fusarium oxysporum f. sp. zingiberi pada jahe (Nurbailis et al. 2015), dan Fusarium spp pada kopi (Mulaw et al. 2013).

Trichoderma dapat berasosasi secara erat dengan sistem perakaran tanaman sehingga disebut sebagai simbiosis avirulen oportunistik. Fase kritis dari asosiasi ini adalah penetrasi ke dalam lapisan luar sel akar tanaman dan menetap pada lapisan tersebut (Samuels et al. 2002; Harman et al. 2004). Selain itu, Trichoderma merupakan endosimbion avirulen yang banyak ditemukan pada jaringan kayu dan daun tanaman tropika seperti Cola spp., Herrania sp., Theobroma spp., dan Hevea spp. (Evans et al. 2003; Chaverri et al. 2011; Rosmana et al. 2015).

Karakteristik spesifik isolat sangat berhubungan dengan inang dan lokasi pengambilan isolat. Isolat lokal dengan karakteristik spesifik berpotensi sebagai agens hayati. Pengendalian hayati bersifat spesifik lokal, yaitu mikroorganisme antagonis yang terdapat di suatu daerah hanya akan memberikan hasil yang baik di daerah asalnya (Erwanti et al. 2003). Prayudi et al. (2000), melaporkan bahwa isolat Trichoderma sp. asal Kalimantan Selatan memiliki kemampuan daya hambat yang lebih baik terhadap penyakit hawar pelepah daun padi pada lahan pasang surut di Kalimatan Selatan dibandingkan dengan isolat asal Yogyakarta. Oleh karena itu, dalam usaha mengendalikan penyakit kopi di Alor, Nusa Tenggara Timur, maka perlu dilakukan identifikasi dan karakterisasi
Trichoderma spp. dari perakaran tanaman kopi di Alor dan menguji kemampuannya sebagai agens hayati untuk menekan penyakit antraknosa.

\section{BAHAN DAN METODE}

\section{Pengambilan Sampel}

Sampel akar diambil dari 5 tanaman kopi sehat di perkebunan kopi kabupaten Alor, Nusa Tenggara Timur (NTT). Sampel dimasukan dalam plastik dan diberi label, dan dibawa ke laboratorium untuk penelitian selanjutnya.

\section{Isolasi dan Identifikasi Trichoderma}

Akar kopi dibersihkan dan dicuci di bawah air mengalir selama \pm 5 menit, kemudian dipotong sebesar $1 \mathrm{~cm} \times 1 \mathrm{~cm}$. Potongan akar disterilkan menggunakan akuades steril, etanol 95\%, dan $\mathrm{NaOCl} 0.5 \%$. Akar dikeringanginkan dan diletakkan pada cawan petri yang telah dilapisi 3 lembar kertas saring basah, kemudian diinkubasi pada suhu kamar selama 7 hari. Cendawan yang tumbuh dari sampel akar dimurnikan pada medium agar-agar dektrosa kentang (ADK) yang ditambahkan streptomisin.

Identifikasi morfologi Trichoderma spp. dilakukan secara makroskopis dan mikrokopis dengan mengamati warna koloni, bentuk koloni, bentuk konidium, klamidiospora, hifa bersekat, konidiofor tegak bercabang dan fialid pendek tebal. Identifikasi cendawan Trichoderma spp. mengacu pada kunci identifikasi Samuels dan Hebbar (2015).

Pengamatan mikroskopis cendawan dilakukan pada mikrokultur. Cawan petri steril diisi dengan 3 lembar tisu (berbentuk bundar) yang telah diteteskan akuades untuk menciptakan kelembaban yang optimum bagi pertumbuhan cendawan. Di atas tisu diletakkan kaca objek yang diberi 1 tetes 
medium ADK yang telah ditumbuhkan spora Trichoderma spp. Kaca objek ditutup dengan kaca penutup, dan diinkubasi pada suhu 25-27 ${ }^{\circ} \mathrm{C}$ selama 3 hari, kemudian diamati menggunakan mikroskop.

\section{Pengujian Antagonisme Trichoderma} terhadap Colletotrichum sp. secara in Vintro Trichoderma hasil isolasi diuji keefektifannya terhadap Colletotrichum asal kakao. Trichoderma asperellum asal kakao digunakan sebagai pembanding. Uji antagonis disusun dalam rancangan acak lengkap (RAL) dengan 6 perlakuan (termasuk kontrol) yang diulang 4 kali. Uji antagonisme pada medium ADK dengan metode kultur ganda. Biakan Trichoderma dan Colletotrichum yang berumur 7 hari ditumbuhkan pada mediun ADK sintetik secara berpasangan dengan jarak antara keduanya ialah $3 \mathrm{~cm}$. Sebagai kontrol digunakan biakan Colletotrichum yang ditumbuhkan tanpa Trichoderma. Kultur tersebut kemudian diinkubasikan pada suhu ruang selama 2 hari.

Pengamatan dilakukan pada 3 dan 5 hari setelah inokulasi dengan mengukur luas koloni cendawan patogen. Selanjutnya diamati pula mekanisme kompetisinya dengan melihat perkembangan cendawan antagonis dan patogen dalam memenuhi cawan petri, dan mekanisme paratisme dilakukan berdasarkan berdasarkan perkembangan hifa cendawan antagonis yang mampu melewati dan menutupi koloni cendawan patogen (Nurbailis et al. 2015).

Persentase penghambatan cendawan dihitung dengan menggunakan rumus:

$$
\mathrm{P}=\frac{\mathrm{R} 1-\mathrm{R} 2}{\mathrm{R} 1} \times 100 \% \text {, dengan }
$$

$\mathrm{P}$, presentase penghambatan $(\%) ; \mathrm{R} 1$, rata-rata diameter Colletotrichum sp. kontrol; R2, ratarata diameter Colletotrichum sp. perlakuan.

\section{Analisis Data}

Data karakterisasi morfospesies yang diperoleh dianalisis deksriptif menurut Semuels dan Hebbar (2015). Data uji antagonisme yang diperoleh dianalisis menggunakan ANOVA dan uji Duncan pada taraf 5\% untuk mengetahui perbedaan perlakuan uji menggunakan program SPSS versi 16.

\section{HASIL}

\section{Karakteristik Mikroskopis dan Makrospesies Morfospesies Trichoderma}

Berdasarkan hasil analisis data deskriptif diperoleh empat morfospesies Trichoderma dari perakaran tanaman kopi asal Alor, Nusa Tenggara Timur. Empat morfospesies dibedakan berdasarkan warna koloni, tetapi bentuk koloninya memiliki kemiripan, yaitu bulat memenuhi medium kultur, hifa berbentuk seperti benang, dan spora menyebar tidak merata pada bagian atas hifa (Gambar 1). Warna koloni bervariasi mulai dari putih hingga putih kehijauan, hijau kekuningan, dan hijau gelap. Warna putih merupakan warna hifa seperti kumpulan benang sedangkan warna hijau merupakan warna spora/konidium (Tabel 1). Pertumbuhan koloni Trichoderma memenuhi seluruh permukaan cawan petri pada 4 hari setelah inokulasi (HSI), kecuali Trichoderma morfospesies 3 (Gambar 2).

Karakteristik mikroskopis empat morfospesies Trichoderma (T-1 sampai T-4) tidak memiliki perbedaan yang menonjol. Bentuk konidiofornya tegak bercabang, konidia oval, hifa bersekat, dan fialid pendek serta tebal. Seluruh klamidiospora yang tiemukan berbentuk agak, tetapi letaknya berbeda. Klamidiospra T-1 terletak pada bagian tengah hifa, T-2 ujung hifa, sedangkan pada T-3 dan T-4 klamidiospora terletak pada tengah dan ujung hifa (Tabel 1).

\section{Antagonisme Trichoderma terhadap Colletotrichum sp.}

Hasil pengujian dual kultur menunjukkan adanya mekanisme kompetisi dan memungkinkan adanya mekanisme parasitisme. Hal ini dilihat dengan pertumbuhan antagonis secara cepat memenuhi cawan petri dan menutupi patogen (Gambar 3). Persen penghambatan Trichoderma secara berturut-turut dari yang tertinggi ialah T-3 (70.2\%), T-2 (65.8\%), dan T-1 (63.3\%). Persen penghambatan seluruh morfospesies Trichoderma berbeda nyata 
dengan perlakuan Trichoderma asperellum, kecuali perlakuan Trichoderma T-3. Semua perlakuan morphospesies Trichoderma berbeda nyata dengan perlakuan $\mathrm{T}-4$ dan kontrol (Tabel 2).

\section{PEMBAHASAN}

Morfologi biakan Trichoderma yang diisolasi dari akar kopi asal Alor NTT memiliki kenampakan makroskopik yang berbeda, tetapi mirip secara mikroskopis. Perbedaan karakteristik makroskopis nampak pada warna koloni di medium ADK. Saat fase kematangan, sebagian besar spesies Trichoderma memiliki warna konidia hijau, dan sedikit spesies yang memiliki warna konidia putih. Warna konidia Trichoderma sp. cukup beragam di antaranya, yaitu kuning kehijauan, coklat kehijauan sampai hijau gelap (Semuels dan Hebbar 2015).
$\mathrm{T}-1$

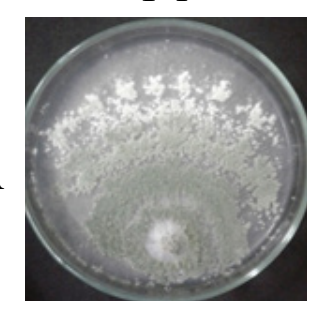

B

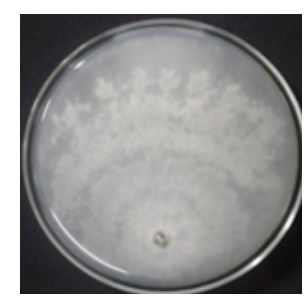

$\mathrm{T}-2$
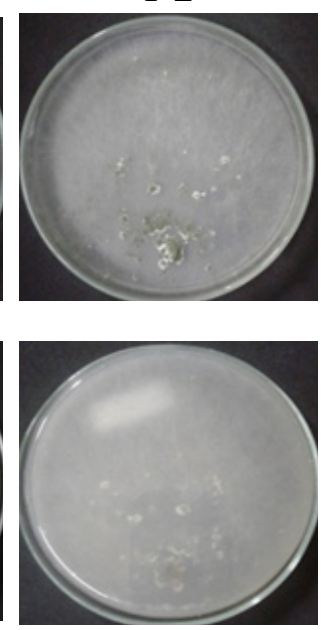

$\mathrm{T}-3$
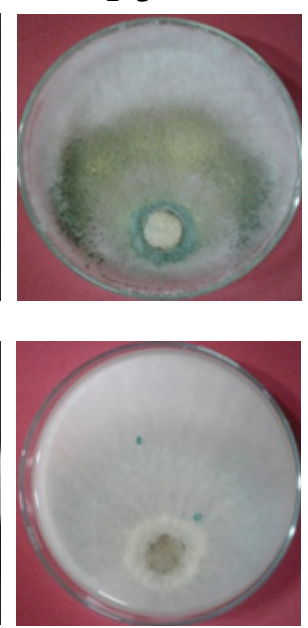

$\mathrm{T}-4$
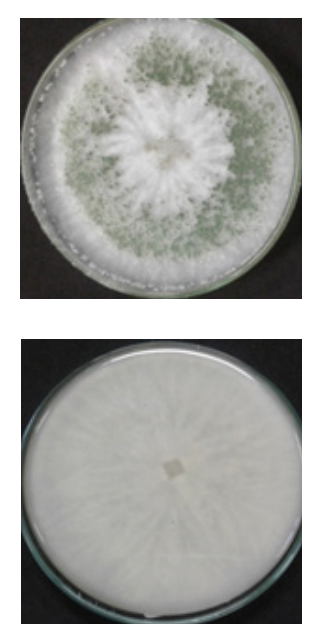

$\mathrm{Ta}$
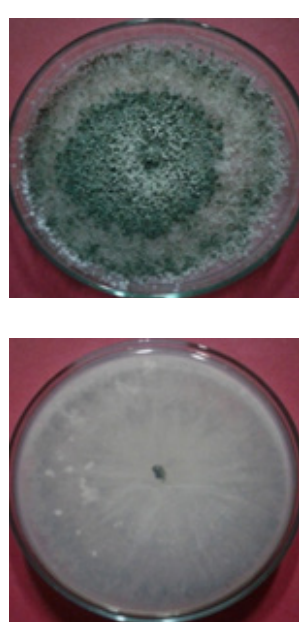

Gambar 1 Empat morfospesies Trichoderma sp. asal akar kopi dan T. asperellum (Ta). T-1; Trichoderma morfospesies 1; T-2, Trichoderma morfospesies 2; T-3, Trichoderma morfospesies 3; T-4, Trichoderma morfospesies 4; A, Tampak atas; dan B, Tampak bawah.

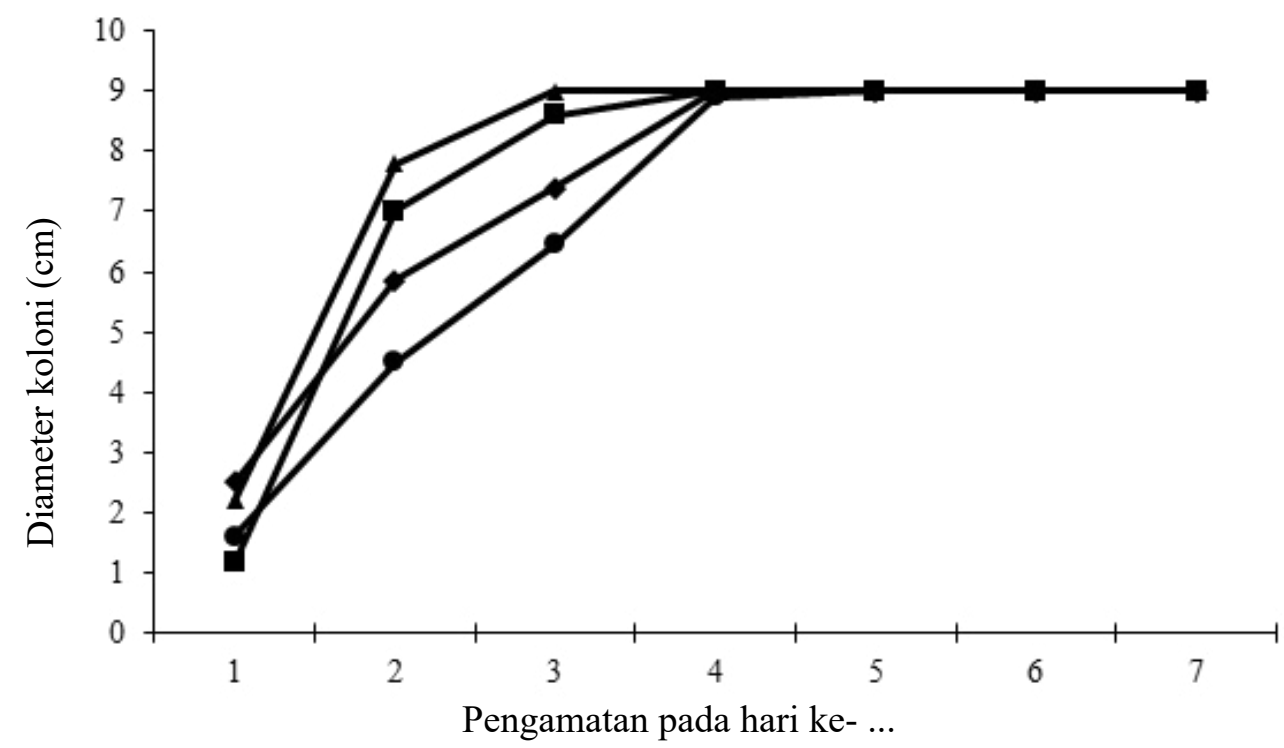

Gambar 2 Grafik rata-rata pertumbuhan koloni cendawan Trichoderma spp selama 7 hari. $\downarrow$, Trichoderma morfospesies 1; $\rightarrow$, Trichoderma morfospesies 2; morfospesies 3; dan $\rightarrow$, Trichoderma morfospesies 4 . 


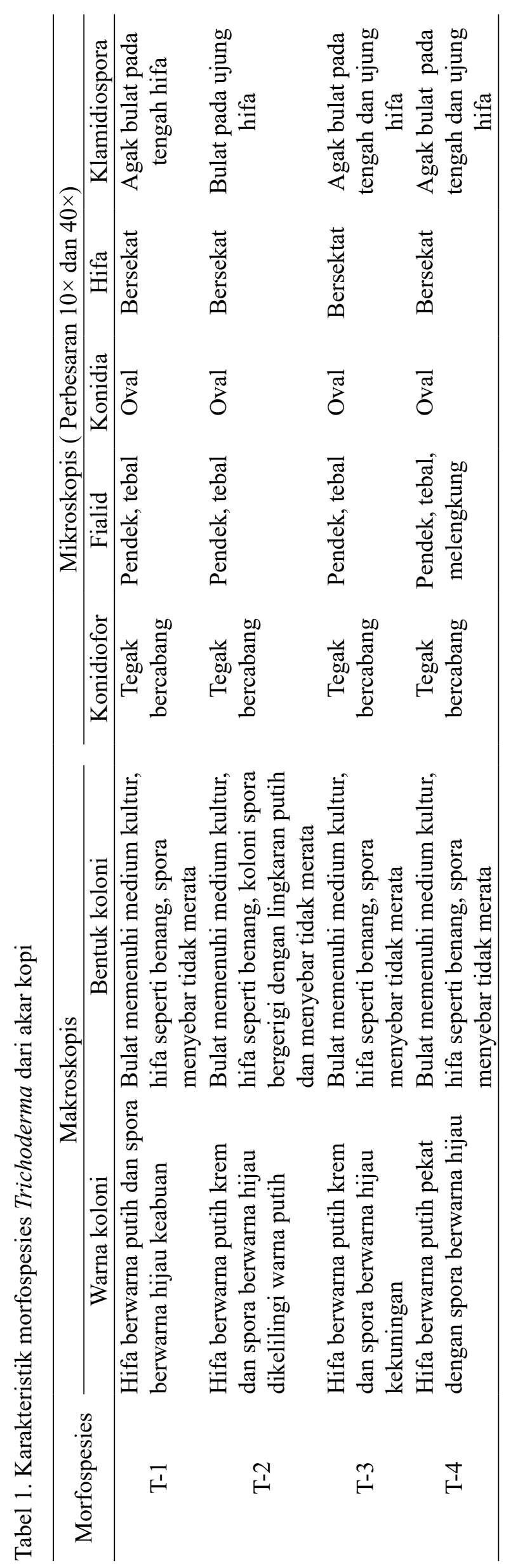



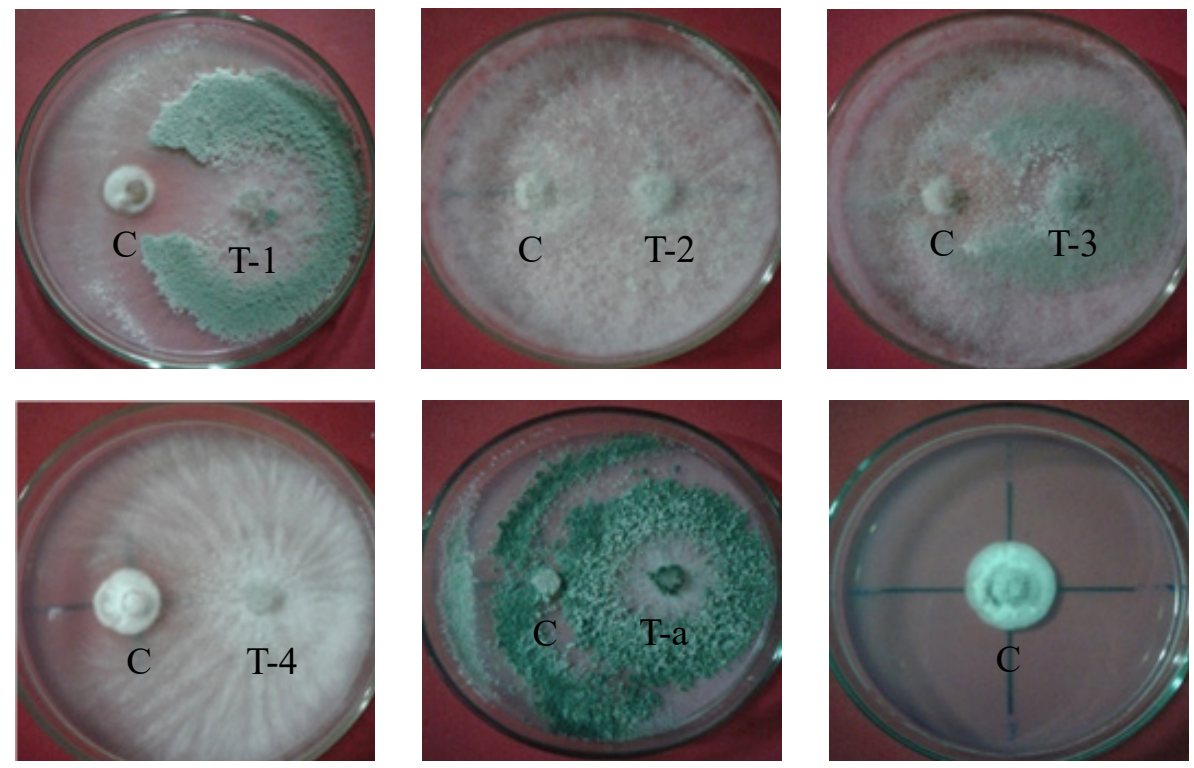

Gambar 3 Model antagonisme beberapa Trichoderma spp terhadap Colletotrichum sp. secara in vitro pada 5 HSI dibandingkan dengan kontrol. T-1; Trichoderma morfospesies 1; T-2, Trichoderma morfospesies 2; T-3, Trichoderma morfospesies 3; T-4, Trichoderma morfospesies 4; Ta, Trichoderma asperellum; dan C, Colletotrichum sp.

Tabel 2 Daya hambat Trichoderma spp. terhadap Colletotrichum sp. secara in vitro

\begin{tabular}{lcc}
\hline \multirow{2}{*}{ Perlakuan } & \multicolumn{2}{c}{ Daya hambat (\%) pada hari ke- ... } \\
\cline { 2 - 3 } & 3 & 5 \\
\hline $\mathrm{T}-1$ & $29.6 \mathrm{bc}$ & $63.3 \mathrm{c}$ \\
$\mathrm{T}-2$ & $34.5 \mathrm{~cd}$ & $65.8 \mathrm{c}$ \\
$\mathrm{T}-3$ & $39.3 \mathrm{~cd}$ & $70.2 \mathrm{~cd}$ \\
$\mathrm{~T}-4$ & $19.3 \mathrm{~b}$ & $43.4 \mathrm{~b}$ \\
$\mathrm{Ta}$ & $45.2 \mathrm{~d}$ & $74.5 \mathrm{~d}$ \\
Kontrol & $0.0 \mathrm{a}$ & $0.0 \mathrm{a}$ \\
\hline Angka-angka yang diikuti oleh huruf yang sama pada \\
kolom yang sama menunjukkan tidak berbeda nyata \\
pada taraf 5\%.
\end{tabular}

Pertumbuhan koloni Trichoderma relatif cepat. Pada 3 HSI hifanya sudah tumbuh memenuhi cawan petri. Alfizar et al. (2013) menjelaskan bahwa pertumbuhan koloni Trichoderma spp. pada medium kultur dapat mencapai diameter 5-6 $\mathrm{cm}$ pada hari ketiga setelah inokulasi.

Karakterisasi mikroskopis morfospesies empat isolat tersebut ialah memiliki bentuk koloni bulat dengan hifa yang bersekat, konidiofor tegak bercabang, fialid tebal dan pendek, bentuk klamidiospora agak bulat dengan bentuk konidia oval. Semuels dan Hebbar (2015) menjelaskan Trichoderma memiliki konidiofor berbentuk hialin dengan ukuran yang beragam, kebanyakan bercabang, tidak semuanya tegak lurus, bentuk fialid tunggal atau berkelompok, memiliki bentuk konidia hialin, bersel satu, berbentuk bulat seperti telur dan bertumpu membentuk tandan kecil.

Trichoderma umumnya dikenal sebagai cendawan antagonis terhadap patogen tanaman. Mekanisme antagonis Trichoderma spp. ialah antibiosis, mikoparasitisme dan kompetisi. Mekanisme antibiosis dapat terjadi karena Trichoderma menghasilkan beberapa toksin mirip antibiotik seperti alametichin, paracelsin, dan tricotoksin yang dapat menghancurkan sel cendawan lainnya melalui perusakan terhadap permeabilitas dinding sel. Disamping itu, Trichoderma juga menghasilkan kitinase dan laminarinase yang dapat menyebabkan lisis dinding sel cendawan lainnya (Gusanawaty et al 2014).

Trichoderma spp. umumnya banyak ditemukan sebagai endofit pada bagian akar dan daun tanaman, di antaranya pada perakaran tanaman kopi. Mulaw et al. (2010) menjelaskan bahwa terdapat keberagaman Trichoderma spp. yang ditemukan sebagai endofit pada akar tanaman kopi (Coffea arabica) di Ethiopia. Spesies cendawan ini 
beragam sesuai dengan kebutuhan nutrisi yang diperoleh dari tanaman inangnya. Cendawan endofit bersimbiosis mutualisme pada inangnya untuk mendapatkan nutrisi dari hasil metabolisme tanaman dan memproteksi tanaman dari herbivora, serangga, atau patogen, sedangkan tanaman mendapatkan derivat nutrisi dan senyawa aktif yang diperlukan selama hidupnya (Simarmata et al. 2007).

Pengujian antagonisme menunjukkan bahwa adanya mekanisme antagonis yang terjadi antara Trichoderma spp. dan Colletotrichum sp. Mekanisme antagonis yang nampak berupa mikoparasit dan kompetisi, serta diduga juga menghasilkan antibiosis untuk menghambat pertumbuhan Colletotrichum sp. Adanya zonasi pada medium kultur merupakan ciri mekanisme antibiosis, tetapi pada pengujian ini tidak begitu nampaknya zonasi antara Trichoderma spp. dan Colletotrichum sp. Hal ini terjadi karena Trichoderma spp. dengan cepat menguasai medium kultur dan menekan perkembangan Colletorichum sp untuk mendapatkan nutrisi. Di samping itu, pertumbuhan cendawan Trichoderma sp. pada perlakuan dapat melewati koloni Colletotrichum sp. sebagai ciri mekanisme mikoparasit, yakni menekan pertumbuhan patogen dengan cara melilit hifa patogen, mengeluarkan enzim $\beta$ 1,3 glukonase dan kitinase yang dapat menembus dinding sel inang dan memarasit sel patogen untuk memperoleh nutrisi (Taufiq 2012; Nurbailis et al. 2015).

Hasil penelitian menunjukkan bahwa semua isolat Trichoderma yang diisolasi dari akar kopi berpotensi menghambat pertumbuhan Colletotrichum sp. Gusnawaty et al. (2014), menjelaskan bahwa Trichoderma spp. asal Sulawesi Tenggara dapat menghambat pertumbuhan Colletotrichum $\mathrm{sp}$. dengan rata-rata persentase pernghambatan $65.07 \%$ $-77.69 \%$ dengan mekanisme kompetisi ruang, mikoparasit dan diduga menghasilkan antibiosis. Namun bila sifat antagonis keempat morfospesies dibandingkan, yaitu T-3 memiliki potensi yang lebih besar, karena memiliki daya hambat terhadap Colletotrichum yang hampir sama dengan Trichoderma asperellum.
Spesies Trichoderma asperellum diketahui efektif mengendalikan penyakit vascular streak dieback dan busuk buah pada kakao (Hakkar et al. 2014; Rosmana et al. 2015).

Dengan demikian, kesimpulan penelitian ini ialah empat morfospesies Trichoderma asal akar kopi memiliki perbedaan karakteristik secara makroskopis dan mikrokopis, serta efektif dalam menghambat pertumbuhan Colletotrichum sp pada medium kultur dengan persentase daya hambat mencapai $70.2 \%$.

\section{UCAPAN TERIMA KASIH}

Penulis mengucapkan terima kasih kepada Lembaga Pengelola Dana Pendidikan (LPDP) selaku penyedia dana pendidikan dan dana penelitian selama penulis melanjutkan studi di Universitas Hasanuddin, Makassar (nomor kontrak:PRJ-1251/LPDP/2015). Disampaikan terima kasih juga kepada pegawai Fakultas Pertanian dan Program Studi HPT, Laboran Laboratorium Penyakit Tumbuhan dan temanteman program Magister IHPT yang telah membantu penulis selama menyelesaikan penelitian ini.

\section{DAFTAR PUSTAKA}

Alfizar A, Marlina M, Susanti F. 2013. Kemampuan antagonis Trichoderma sp. terhadap beberapa jamur patogen in vitro. J Floratek. 8(1):45-51.

Chaverri P, Gazis RO, Samuels GJ. 2011. Trichoderma amazonicum, a new endophytic species on Hevea brasiliensis and $H$. guianensisfrom the Amazon basin. Mycologia. 103:139-151. DOI: https:// doi.org/10.3852/10-078.

Erwanti, Mardius Y, Habazar T, Bachtiar A. 2003. Studi kemampuan isolat-isolat jamur Trichoderma spp. yang beredar di Sumatera Barat untuk mengendalikan jamur patogen Sclerotium roflsii pada bibit cabai. Prosiding Kongres Nasional XVI dan Seminar Ilmiah PFI; 2003 Agu 22-24. Bogor.

Evans HC, Holmes KA, Thomas SE. 2003. Endophytes and mycoparasites associated 
with an indigenous forest tree, Theobroma gileri, in Ecuador and a preliminary assessment of their potential as biocontrol agents of cocoa diseases. Mycological Progress. 2(2):149-160. DOI: https://doi. org/10.1007/s11557-006-0053-4.

Gusnawaty H, Taufik M, Herman H. 2014. Efektifitas Trichoderma indigenus Sulawesi Tenggara sebagai biofungisida terhadap Colletotrichum sp. secara invitro. Jurnal Agroteknos. 4(1):38-43.

Hakkar AA, Rosmana A, Rahim MD. 2014. Pengendalian penyakit busuk buah Phytophthora pada kakao dengan cendawan endofit Trichoderma asperellum. J Fitopatol Indones. 10:139-144. DOI: https://doi.org/10.14692/jfi.10.5.139.

Harman GE, Howell CR, Viterbo A, Chet I, Lorito M. 2004. Trichoderma species -opportunistic, avirulent plant symbionts. Nature reviews microbiology. 2(1):43-56. DOI: https://doi.org/10.1038/nrmicro797.

Mulaw TB, Kubicel CP, Druzhinina IS. 2010. The rhizozphereof coffea arabica in its native highland forests of Ethiopia provides a niche for a distinguished diversity of Trichoderma. Diversity. 2:527-549. DOI: https://doi.org/10.3390/d2040527.

Mulaw TB, Druzhinina IS, Kubicel CP, Atanasova L. 2013. Novel endophytic Trichoderma spp. isolated from healthy coffea arabica roots are capable of controlling coffee tracheomycosis. Diversity. 5:750-766. DOI: https://doi. org/10.3390/d5040750.

Nurbailis, Winarto, Panko A. 2015. Penapisan cendawan antagonis indigenos rizosfer jahe dan uji daya hambatnya terhadap
Fusarium oxysporum f. sp. zingiberi. J Fitopatol Indones. 11:9-13. DOI: https:// doi.org/10.14692/jfi.13.1.9.

Prayudi B, Budiman A, Rystham MA, Rina Y. 2000. Trichoderma harzianum isolat Kalimantan Selatan agensia pengendali hawar pelepah daun padi dan layu semai kedelai di lahan pasang surut. Prosiding Simposium Penelitian Tanaman Pangan $I V$; Banjarbaru.

Rosmana A, Samuels GJ, Ismaiel A, Ibrahim ES, Chaverri P, Herawati Y, Asman A. 2015. Trichoderma asperellum: a dominant endophyte species in cacao grown in Sulawesi with potential for controlling vascular streak dieback disease. Tropical Plant Pathology. 40(1):19-25. DOI: https:// doi.org/10.1007/s40858-015-0004-1.

Samuels GJ, Dodd SL, Gams W, Castlebury LA, Petrini O. 2002. Trichoderma species associated with the green mold epidemic ofcommercially grown Agaricus bisporus. Mycologia. 94:146-170. DOI: https://doi. org/10.1080/15572536.2003.11833257.

Samuels GJ, Hebbar PK. 2015. Trichoderma, Identification and Agricultural Application. Minnesota (US): APS.

Simarmata R, Lekatompessy S, Sukiman H. 2007. Isolasi mikroba endofitik dari tanaman obat sambung nyawa (Gynura procumbens) dan analisis potensinya sebagai antimikroba. Berk Penel Hayati. 13:85-90. DOI: https://doi.org/10.23869/ bphjbr.13.1.200714.

Taufiq E. 2012. Potensi Trichoderma spp dalam menekan perkembangan penyakit busuk pucuk vanili di pembibitan. Buletin RISTRI. 3:49-56. 